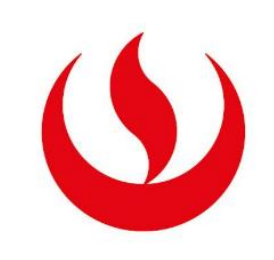

UNIVERSIDAD PERUANA DE CIENCIAS APLICADAS

FACULTAD DE CIENCIAS DE LA SALUD

PROGRAMA ACADÉMICO DE NUTRICIÓN Y DIETÉTICA

Una aproximación cualitativa a los motivos de consumo de productos

ultraprocesados de máquinas expendedoras en estudiantes de una universidad privada de Lima, Perú

\title{
TESIS
}

Para optar el título profesional de Licenciado en Nutrición y Dietética

\section{AUTOR (ES)}

Del Aguila Flores, Luz Jasmine (0000-0002-8045-2212)

Nuñez Paucar, Tania Shandini (0000-0002-3206-5488)

\section{ASESOR}

Uribe Chincha, Tula Gloria (0000-0003-1654-2835)

Lima, 31 de Agosto del 2020 
DEDICATORIA

A nuestras familias, en especial a nuestros padres por darnos la fuerza, el apoyo y el amor necesario para hacer cumplir nuestras metas. 


\section{AGRADECIMIENTOS}

A Dios por brindarnos salud y la determinación de seguir adelante.

A nuestros padres por la confianza depositada en nosotras.

A nuestra asesora Tula Gloria Uribe Chincha, por brindarnos su tiempo, conocimientos y siempre sabernos guiar. 


\section{RESUMEN}

Introducción: En los últimos años, los patrones alimenticios de la población han cambiado tanto en países desarrollados como en los de vías de desarrollo. Esto debido a la urbanización y globalización de los mercados, y por consiguiente, ha causado el reemplazo de los alimentos tradicionales o mínimamente procesados por alimentos ultraprocesados en la dieta diaria. Incluso, se ha evidenciado que uno de los medios más convenientes para la adquisición de estos productos son las máquinas expendedoras.

Objetivo: Explorar los motivos de consumo de productos ultraprocesados en máquinas expendedoras en estudiantes de una universidad privada en Lima.

Método: Es un estudio cualitativo de diseño fenomenológico. Se realizaron 40 listados libres, 18 entrevistas a profundidad y 2 grupos focales a universitarios mayores de 18 años utilizando guías de preguntas. La muestra fue de 66 personas seleccionadas por conveniencia hasta llegar al punto de saturación.

Resultados: El producto más consumido de las máquinas expendedoras fueron las papas fritas picantes. Los motivos de consumo de productos ultraprocesados en máquinas expendedoras fueron el sabor, horario académico, la cercanía, la accesibilidad, el precio, la facilidad y rapidez. También, se evidenció que el estado de ánimo, como estrés, ansiedad, tristeza y depresión influye en el proceso de compra de estos productos.

Conclusión: A pesar de que los estudiantes saben y conocen que los productos ultraprocesados son perjudiciales para la salud los siguen consumiendo principalmente por el sabor, horario académico, el precio, la accesibilidad y la rapidez hacia ellos.

Palabras clave: Motivos; consumo; máquinas expendedoras; universitarios. 
A approach qualitative to the reasons for consumption of ultra-processed products from vending machines in students from a private university in Lima, Peru

\begin{abstract}
Introduction: Currently, the eating patterns of the population have changed both in changed countries and on development paths. This is due to the urbanization and globalization of markets, and as far as it is concerned, it has the replacement of traditional or minimally processed foods with ultra-processed foods in the daily diet. In addition, it has been shown that one of the most convenient means of acquiring these products is vending machines.
\end{abstract}

Objective: Exploring the reasons for consuming ultra-processed products in vending machines in students from a private university in Lima.

Methods: A qualitative study of phenomenological design. We were used 40 free guides, 18 in-depth interviews and 2 focus groups for university students over 18 using question guides. The sample was 66 people selected for convenience until reaching the saturation point.

Results: The most consumed product of vending machines was spicy potato chips. The reasons for consuming ultra-processed products in vending machines were the taste, academic hours, proximity, accessibility, price, ease and speed. Also, it is evident that mood, such as stress, anxiety, sadness and depression influence the purchasing process of these products.

Conclusion: Although the students know and have to receive the ultra-processed products, they are harmful to health, those who continue consuming mainly due to the taste, the academic schedule, the price, the accessibility and the speed towards them.

Keywords: Motives; Consumption; vending machines; university students. 
1. INTRODUCCIÓN .....................................................................................................9

2. PREGUNTA DE INVESTIGACIÓN .....................................................................11

3. JUSTIFICACIÓN.......................................................................................................... 11

4. OBJETIVOS ………….................................................................................................................... 11

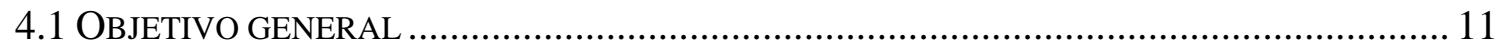

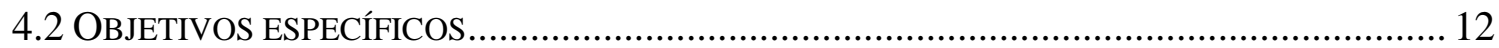

5. METODOLOGÍA...............................................................................................

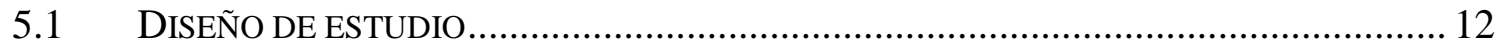

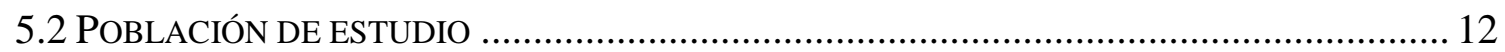

5.3 CRITERIOS DE INCLUSIÓN Y EXCLUSIÓN.................................................................. 12

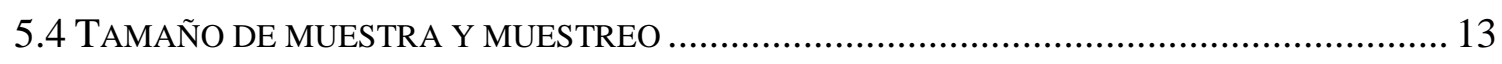

5.5 CATEGORÍAS: Dimensiones Y EJES TEMÁticos...................................................... 13

5.6 TÉCNICAS E INSTRUMENTOS UTILIZADOS................................................................. 14

5.7 RECOLECCIÓN DE LA INFORMACIÓN ……………………………………………... 14

6. ANÁLISIS DE DATOS ......................................................................................16

7. ASPECTOS ÉTICOS, ADMINISTRATIVOS Y REGULATORIOS......................16

8. RESULTADOS .......................................................................................................................... 17

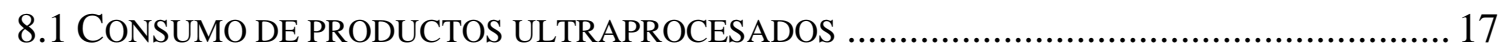

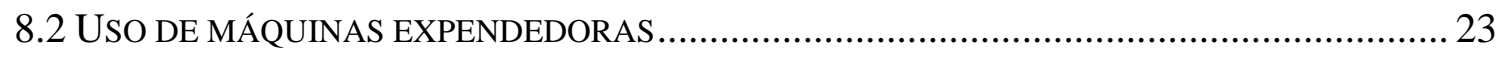

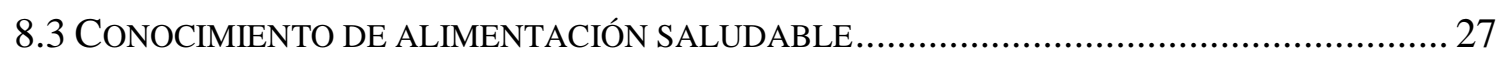

9. DISCUSIÓN ..........................................................................................................32

10. LIMITACIONES Y FORTALEZAS.........................................................................35

11. CONCLUSIÓN ……....................................................................................................36

12. RECOMENDACIONES .............................................................................................36

13. REFERENCIAS BIBLIOGRÁFICAS ….....................................................37

14. ANEXOS ….......................................................................................................................... 40 
14.1 INSTRUMENTO DE RECOLECCIÓN DE DATOS 40

14.2 CONSENTIMIENTO / ASENTIMIENTO INFORMADO U HOJA INFORMATIVA...................... 44 


\section{ÍNDICE DE TABLAS}

Tabla 1. Productos ultraprocesados de las máquinas expendedoras más consumidos por los estudiantes de la Universidad Peruana de Ciencias Aplicadas (UPC) 18

Tabla 2. Clasificación de los productos ultraprocesados de las máquinas expendedoras* más consumidos por los estudiantes de una universidad privada de Lima, Perú 19 


\section{INTRODUCCIÓN}

Año tras año, a raíz de la urbanización y la globalización de los mercados, los regímenes alimentarios de la población han cambiado tanto en países desarrollados como en los de vías de desarrollo (1). Lo que ha llevado a que se genere una transición nutricional, y con ello, el reemplazo de la alimentación tradicional, compuesta por alimentos sin procesar o mínimamente procesados, por una dieta hipercalórica basada en productos ultraprocesados, los cuales son altos en grasas, sodio y azúcares simples $(2,3)$. Es así como las demandas y los patrones de alimentación de las zonas urbanizadas han migrado hacia productos más convenientes y preparados $(4,5)$. Esto ha generado que la venta y el consumo de este tipo de productos tenga un gran crecimiento en los últimos años. Según la Organización Panamericana de Salud (OPS), a nivel mundial, durante los años 2000 - 2013, la venta de los productos ultraprocesados aumentó un $43.7 \%$ (6). Además, en los últimos estudios realizados en siete países latinoamericanos, incluyendo Perú, se ha podido observar que las ventas han seguido este patrón ascendente y se proyectó un crecimiento de $9.2 \%$ para el 2019. Asimismo, se informó que nuestro país era el de mayor crecimiento ( $15.6 \%$ per cápita/día) y se espera que la tasa de crecimiento sea relativamente similar durante el periodo 2015 y 2019 (7).

Además, se ha evidenciado que uno de los medios más convenientes para comprar este tipo de productos son las máquinas expendedoras y uno de los lugares de más consumo son los centros de estudio (8). No obstante, un alto porcentaje de los productos comercializados en este tipo de máquinas (80.5\%) son poco saludables (9). En un estudio realizado en España, se evalúo la calidad nutricional de los productos presentes en máquinas expendedoras, y se obtuvo como resultado que dichos productos se excedían en varios parámetros como grasa y sal. Por ende, la calidad de estos productos no podía ser definida como saludable (10), teniendo como concepto que una alimentación saludable es una alimentación variada idealmente con alimentos naturales o mínimamente procesados que aporten todos los nutrientes necesarios para mantenerse sano (11). Otro estudio que refuerza lo antes mencionado, es uno realizado en Canadá, donde se observó que, la presencia de máquinas expendedoras de bebidas estaba asociada con índices de peso y comportamiento alimentario inadecuados (12).

Todos estos productos llamados ultraprocesados, de consumirse en exceso, causan que una persona sana pueda llegar a sufrir de alguna enfermedad no transmisible (ENT) y sobrepeso 
u obesidad, que afectan la salud y el estilo de vida. Solo las ENT causan el $71 \%$ de las muertes alrededor del mundo (13), y en el Perú representan más del 50\% de las enfermedades con mayor incidencia (14), provocando, además de muertes prematuras, un mayor gasto en salud y un aumento del riesgo de presentar alguna discapacidad en el futuro (15). Por otro lado, el sobrepeso y obesidad ha aumentado tres veces su número desde 1975 (16), y ha ido creciendo progresivamente en todos los grupos etarios en nuestro país. Como se puede apreciar en el documento, Perú: Enfermedades No Transmisibles y Transmisibles, en el 2019 , el $37.8 \%$ de personas mayores de 15 años presentaba sobrepeso y $22.3 \%$ obesidad (17). Este tipo de enfermedades tienen diversos factores de riesgo (13), la mayoría de ellos asociados a comportamientos que pueden ser modificables, solo dependen, en gran medida, de la decisión y compromiso de las personas para corregirlos.

Las causas o motivos del consumo de este tipo de productos no son muy estudiados y varían dependiendo de distintos factores. Así pues, en un estudio realizado en Arabia Saudita en estudiantes universitarios se encontró que del 28.2\% que sufrían de estrés tenían una mayor tendencia a consumir comida no saludable o "chatarra" (62.8\%). Asimismo, el estudio mostró que preferían el consumo de estos alimentos por el sabor y su fácil acceso (18). En otro estudio, esta vez realizado en Kuwait en estudiantes universitarios, se encontró que la mayoría de ellos (44\%) conocían el bajo valor nutricional de las comidas rápidas y que la razón principal de consumir este tipo de alimentos fue el gusto agradable (19). Además, un estudio de México, en donde entrevistaron a 10 hombres entre los 25 y 32 años, mostró que la razón principal de compra fue la durabilidad del producto, así como el tiempo y la accesibilidad (20). Con ello notamos la importancia de conocer o explorar los motivos de consumo, ya que el conocerlos hará que se creen estrategias de salud más eficaces y duraderas que den soluciones al problema de la alta demanda de productos ultraprocesados.

Finalmente, para este estudio consideramos como snacks todo alimento o bebida que se consumen entre comidas (21). De igual manera, los alimentos procesados consideramos como todos aquellos mínimamente procesados y que se les añade grasas, azucares, sal y otros ingredientes para hacerlos más perecibles y sabrosos. Además, los productos ultraprocesados como aquellos que se preparan de formulaciones industriales a partir de sustancias de los alimentos o sintetizados de otras fuentes. Estos productos contienen pocos o ningún alimento entero (6). 


\section{PREGUNTA DE INVESTIGACIÓN}

¿Cuáles son los motivos de consumo de productos ultraprocesados de máquinas expendedoras en estudiantes de una universidad privada de Lima?

\section{JUSTIFICACIÓN}

En nuestro país, las cifras de sobrepeso y obesidad se han incrementado significativamente año tras año. Hemos pasado de $35.5 \%$ de sobrepeso en personas mayores de 15 años en el 2015 a $37.8 \%$ en el 2019 y de $17.8 \%$ de personas mayores de 15 años con obesidad en el 2015 a $22.3 \%$ en el 2019 , por lo que son considerados como una pandemia a nivel mundial $(17,22)$. Lo cual los convierte en un problema de salud pública que afecta cada vez a más jóvenes mayores de 15 años tanto en el Perú como en el mundo. Por otro lado, uno de los factores que contrarrestarían que los porcentajes de prevalencia no disminuyan, es la alimentación no saludable, más aún en jóvenes, pues se ha evidenciado que optan por productos ultraprocesados. Además, la calidad de estos productos que se expenden en máquinas expendedoras ha sido implicado como factor que conlleva al desarrollo de un ambiente alimentario obesogénico (23). Tal como se demuestra en un estudio realizado en el Reino Unido, cuyo objetivo fue examinar el valor nutricional de los alimentos que se vendían en dichas máquinas. En el estudio se evaluaron nueve máquinas expendedoras del campus cuyo resultado arrojó que la mayoría de los productos disponibles eran de baja calidad (24). Por todo lo expuesto, resulta trascendental conocer cuáles son las razones para que los universitarios adquieran estos productos. Por ello, el objetivo principal de nuestra investigación es explorar los motivos de consumo de los productos ultraprocesados en máquinas expendedoras.

\section{OBJETIVOS}

\subsection{Objetivo general}

1. Explorar los motivos de consumo de productos ultraprocesados en máquinas expendedoras en el periodo 2018-2 en estudiantes de una universidad privada en Lima, Perú. 


\subsection{Objetivos específicos}

1. Describir los productos ultraprocesados de mayor consumo en las máquinas expendedoras de una universidad privada de Lima, Perú en el periodo 2018-2.

2. Identificar los motivos de consumo de productos ultraprocesados en las máquinas expendedoras en estudiantes de una universidad privada en Lima, Perú en el periodo 2018-2.

\section{METODOLOGÍA}

\subsection{Diseño de estudio}

Se realizó un estudio cualitativo con diseño fenomenológico, que busca la comprensión e interpretación del fenómeno a partir de la experiencia de los participantes. Este tipo de estudio se basa en analizar los discursos para poder describir y entender la situación desde el punto de vista del estudiante y desde la idea que se elabora colectivamente (25).

\subsection{Población de estudio}

El estudio se realizó en mujeres y varones mayores de 18 años, estudiantes de la Universidad Peruana de Ciencias aplicadas (UPC), sede Villa ubicada en el distrito de Chorrillos.

\subsection{Criterios de inclusión y exclusión}

- Criterio de inclusión:

- $\quad$ Estudiantes de la UPC que estén cursando el semestre 2018-02.

- $\quad$ Estudiantes de la UPC mayores de 18 años pertenecientes al campus Villa.

- $\quad$ Estudiantes de la UPC que mediante un consentimiento informado deseen participar en la investigación.

\section{- Criterio de exclusión:}

- $\quad$ Estudiantes de la UPC que no adquieran productos de las máquinas expendedoras.

- $\quad$ Estudiantes de la UPC pertenecientes a la carrera de Nutrición y Dietética. 
5.4 Tamaño de muestra y muestreo

La muestra fue seleccionada por conveniencia. Los participantes fueron elegidos por accesibilidad y disponibilidad de las investigadoras. El número de participantes fue de 66 estudiantes, lo cual se determinó al llegar al punto de saturación, es decir, cuando la información que se obtiene se torna repetitiva y coincidente (26).

Se seleccionaron 4 máquinas expendedoras, para ello se hizo una observación rápida de las máquinas existentes en el campus, identificándose que las maquinas más utilizadas fueron aquellas ubicadas entre los pabellones $\mathrm{A}, \mathrm{G}, \mathrm{H}, \mathrm{I}$, por ser céntricas, las más concurridas y por donde los estudiantes transitan frecuentemente.

5.5 Categorías: Dimensiones Y Ejes Temáticos

\begin{tabular}{|c|c|c|c|}
\hline Categorías & Definición & Dimensión & Ejes Temáticos \\
\hline Conocimiento & $\begin{array}{c}\text { Son hechos } \\
\text { o información } \\
\text { adquirida por una } \\
\text { persona. }\end{array}$ & Alimentación & 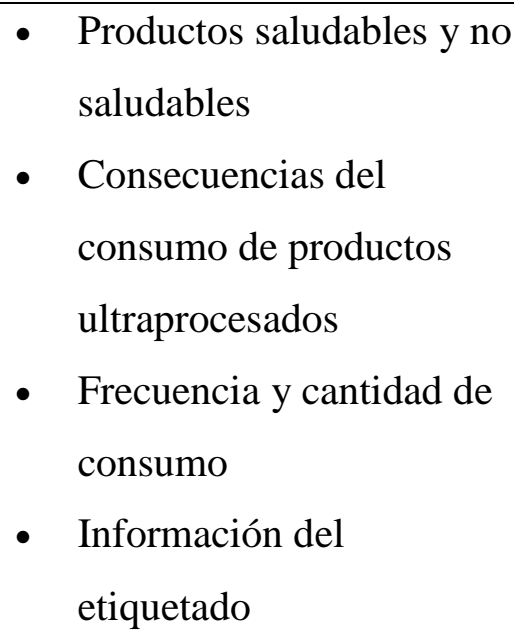 \\
\hline \multirow[t]{2}{*}{$\begin{array}{c}\text { Razones o } \\
\text { motivaciones }\end{array}$} & \multirow[t]{2}{*}{$\begin{array}{c}\text { Causa o motivo de una } \\
\text { acción. }\end{array}$} & $\begin{array}{l}\text { Decisión de } \\
\text { compra }\end{array}$ & $\begin{array}{ll}\text { - } & \text { Costo } \\
\text { - } & \text { Tiempo } \\
\text { - } & \text { Gustos y/o preferencias } \\
\text { - } & \text { Acceso a máquinas } \\
\text { expendedoras } \\
\text { - } \text { Practicidad } \\
\text { - Publicidad }\end{array}$ \\
\hline & & $\begin{array}{c}\text { Momentos de } \\
\text { consumo }\end{array}$ & $\begin{array}{l}\text { - Estudios, prácticas o } \\
\text { exámenes } \\
\text { - Aburrido }\end{array}$ \\
\hline
\end{tabular}




\begin{tabular}{|l|l|l|l|}
\hline & & & Estresado \\
& & & Ansiedad \\
\hline
\end{tabular}

5.6 Técnicas e instrumentos utilizados

- Listado libre de productos ultraprocesados, este instrumento es una adaptación del listado libre y permite saber mediante una lista, cuales son los productos más consumidos por cada uno de los estudiantes (27). Para el estudio se aplicaron un total de 40 listados de productos ultraprocesados.

- Entrevistas a profundidad, fueron aplicadas a 18 estudiantes. Está técnica se usa con el fin de extraer información relevante para el tema de investigación (28).

- Grupos focales, se realizaron 2 grupos focales, uno conformados por varones y el otro por mujeres de 6 estudiantes cada uno, para que ambos grupos puedan expresar libremente sus opiniones. Esto permitió ver las similitudes y discrepancias que existían con la información captada en las entrevistas a profundidad (28).

- Guías de preguntas, es el instrumento que se utilizó para realizar las entrevistas, así como los grupos focales. Las guías de preguntas se elaboraron en función de la tabla de categorías, dimensiones y ejes temáticos. Para el presente estudio dicha guía de preguntas fue elaborada por las investigadoras y revisada por la asesora. Además, las guías fueron validadas para evaluar la compresión de las preguntas con 10 estudiantes quienes no fueron parte del estudio. Asimismo, a partir de la validación se realizaron las correcciones necesarias. La guía de preguntas para las entrevistas a profundidad y la de grupos focales contaron con 27 y 30 preguntas respectivamente, las cuales abarcan todos los temas y responden a nuestros objetivos.

Para evitar sesgos y dar rigor al estudio, la información se trianguló mediante las técnicas empleadas para el recojo de la información y entre investigadoras (29).

\subsection{Recolección de la información}

La recolección de la información se realizó en el semestre 2018-02, pero antes de iniciar con el recojo de la información se realizaron los siguientes pasos:

- Se realizó una validación del listado libre de productos ultraprocesados, las guías de entrevista a profundidad y grupo focal, para evaluar la comprensión de las preguntas 
y realizar las correcciones correspondientes, dicha evaluación se realizó con un total de 20 alumnos que cumplían con las características de la muestra pero que no fueron parte de la investigación.

- A todos los estudiantes que se abordaron se les explicó los objetivos del estudio, para luego preguntarles si deseaban participar, independientemente del instrumento que se les aplicaría.

- Asimismo, se les informó a los estudiantes a quienes se les aplicó la entrevista y aquellos que participaron en los grupos focales que todo lo conversado se grabaría en audio con ayuda de un smartphone para su posterior transcripción y análisis. Asimismo, se les explicó que toda la información recibida se mantendría en confidencialidad.

- De aceptar participar se les entregaba el consentimiento informado para su firma y así poder aplicar el instrumento pertinente.

\section{Listado libre de productos ultraprocesados}

Para la aplicación del listado libre, se abordaron a los alumnos una vez que terminaban de hacer su compra en las máquinas expendedoras y se les preguntaba ¿Cuáles son los productos que más compras o consumes de esta máquina? Una vez que nos mencionaban los nombres de los productos lo anotábamos en los registros para su posterior análisis.

\section{Entrevista a profundidad}

Para las entrevistas a profundidad se utilizó una guía de preguntas, elaborada para el presente estudio por las investigadoras. Las entrevistas a profundidad se realizaron de forma individual y abordaban tres temas: conocimientos sobre alimentación y productos ultraprocesados, uso de máquinas expendedoras y razones o motivación para la decisión de compra. Las preguntas se realizaban en forma de conversación y se agregaban de acuerdo con el criterio de las investigadoras. Además, todas las entrevistas fueron grabadas en audio a través de un smartphone. El tiempo de duración de las entrevistas a profundidad fue aproximadamente de veinte a treinta minutos.

\section{Grupos focales}


Por último, se realizaron 2 grupos focales, uno de mujeres y otro de hombres. Para ello, se reunieron a 6 personas, las cuales fueron llevadas a un ambiente cerrado de la UPC, para evitar cualquier tipo de ruido o distracción. Para estas entrevistas también se utilizó una guía de preguntas, elaborada para el presente estudio por las investigadoras. El objetivo fue verificar los consensos o disensos de la información obtenida en las entrevistas a profundidad. La duración fue de cuarenta y cinco minutos a una hora aproximadamente.

\section{ANÁLISIS DE DATOS}

Obtenida la información, estas se procesaron de acuerdo con la técnica empleada. En primer lugar, con la información del listado libre se formaron cuadros y listas, donde se detalló los productos mencionados por cada estudiante. Luego de ello, fueron clasificados en orden según las veces mencionadas y se obtuvieron los productos ultraprocesados más consumidos por los alumnos.

Con respecto a las entrevistas a profundidad y los grupos focales, una vez de obtenida la información, se realizó la transcripción textual de las grabaciones a un programa de Microsoft Word Office versión 2013. Luego de ello, se procedió a la lectura de la información recolectada para luego elaborar una matriz de doble entrada, con el fin de tener el panorama de la información e iniciar el análisis. Después se identificaron las categorías y subcategorías, las cuales se codificaron, se relacionaron y se formaron categorías más grandes. Por último, se procedió a redactar los resultados.

\section{ASPECTOS ÉTICOS, ADMINISTRATIVOS Y REGULATORIOS}

El estudio fue revisado y aprobado por el comité de ética de la Universidad Peruana de Ciencias Aplicadas (UPC) (FCS/CEI 089-05-20). A los participantes se les entregó un consentimiento informado, con el fin de informarles el propósito del estudio e indicarles que tienen libertad de abandonarlo en cualquier momento, así mismo se les informó que las entrevistas y grupos focales serían grabadas en audio pero que se mantendría en absoluta reserva y será usada sólo para fines del estudio. Cuando aceptaron participar se solicitó su firma en el consentimiento informado. Por otro lado, toda la información fue analizada solo 
por las investigadoras y a cada uno de los participantes se les asignó un código para salvaguardar su identidad. Una vez concluido el estudio, toda la toda información grabada fue eliminada, sin dejar rastro alguno.

Por último, al finalizar el proceso de recolección se brindó una consejería nutricional sobre consumo de productos ultraprocesados. El tema que se abordó fue las consecuencias del consumo frecuente de este tipo de productos, problemas de obesidad y sobrepeso, y sus implicancias en la salud. Se utilizó la información de apoyo del Ministerio de Salud (MINSA) y otras fuentes relevantes $(30,31,32,33)$.

\section{RESULTADOS}

El estudio se realizó con 66 estudiantes, 34 mujeres y 32 hombres de la Universidad Peruana de Ciencias Aplicadas (UPC), campus Villa. Las edades de los participantes fluctuaron entre 18 y 23 años. Ellos provenían de distintas carreras, tales como psicología, ingeniería civil, administración y negocios internacionales, administración y marketing, medicina, arquitectura, gestión minera, comunicación audiovisual, administración y agronegocios.

Se realizaron en total, 40 listados libres, 18 entrevistas a profundidad y 2 grupos focales con 6 integrantes cada uno. La recolección de la información se realizó en el mes de Setiembre 2018. A partir del análisis temático se obtuvieron tres categorías principales: Consumo de productos ultraprocesados, uso de máquinas expendedoras y conocimiento de alimentación saludable.

\subsection{Consumo de productos ultraprocesados}

El consumo de productos ultraprocesados se observa como un patrón en la mayoría de los estudiantes. Se pudo apreciar que los productos más consumidos en las máquinas expendedoras son un total de dieciséis (Tabla 1). Esto se determinó, debido a que, fueron mencionados de tres a más veces por los cuarenta estudiantes que participaron en el listado libre. Entre los productos más nombrados destacan las Hojuelas de papas fritas sabor picante, goma de mascar sin azúcar, galletas de vainilla bañadas parcialmente en cobertura sabor a chocolate, caramelos refrescantes y maní salado, los cuales se encuentran entre los primeros cinco productos más consumidos y/o mencionados. 
Tabla 1. Productos ultraprocesados de las máquinas expendedoras más consumidos por los estudiantes de la Universidad Peruana de Ciencias Aplicadas (UPC)

Productos más consumidos

Hojuelas de papas fritas con sabor picante

Goma de mascar sin azúcar

Galletas de vainilla bañadas parcialmente en cobertura sabor a chocolate

Caramelos refrescantes

Maní salado

Galleta con cereales, cacao y fibra

Galleta sabor a vainilla bañadas con pasta sabor chocolate

Galletas saladas

Galleta con chispas sabor a chocolate

Mini galletas saladas

Galletas de vainilla bañadas con sabor chocolate y grageas de colores

Galletas rellenas de crema con coco natural

Galletas con trigo integral con sabor a miel

Doble galleta de chocolate rellenas con crema sabor a vainilla

Bizcocho relleno con manjar y cobertura sabor chocolate

Bebida de durazno

La frecuencia de este tipo de productos eran de máximo 3 o 4 paquetes al día, a su vez se encontró que al agruparlos según el Modelo de perfil de nutrientes de la Organización Panamericana de la Salud (34) (Tabla 2) los productos se agrupan en 5 categorías. Estos son: snacks dulces o salados envasados, galletas, caramelos y golosinas, bizcochos, mezclas para bizcochos y barras de cereales y jugos envasados. Entre los cuales se puede diferenciar el consumo mayoritario de galletas, las cuales suelen contener más cantidad brindando al consumidor una sensación mayor de llenura comparado con otros productos. Es precisamente esta razón, la que algunos estudiantes mencionaron ante el consumo de este 
producto en específico. Por otro lado, todos los productos mencionados al tener un alto contenido de azúcar, grasa y sodio son de una alta densidad energética, lo cual favorece al desarrollo del sobrepeso y obesidad.

Tabla 2. Clasificación de los productos ultraprocesados de las máquinas expendedoras* más consumidos por los estudiantes de una universidad privada de Lima, Perú

\section{Clasificación de productos ultraprocesados más consumidos}

\section{Snacks dulces o salados envasados}

Hojuelas de papas fritas con sabor picante

Maní salado

\section{Galletas}

Galletas de vainilla bañadas parcialmente en cobertura sabor a chocolate

Galleta con cereales, cacao y fibra

Galleta sabor a vainilla bañadas con pasta sabor chocolate

Galletas saladas

Galleta con chispas sabor a chocolate

Mini galletas saladas

Galletas de vainilla bañadas con sabor chocolate y grageas de colores

Galletas rellenas de crema con coco natural

Galletas con trigo integral con sabor a miel

Doble galleta de chocolate rellenas con crema sabor a vainilla

\section{Caramelos y golosinas}

Goma de mascar sin azúcar

Caramelos refrescantes

Bizcochos, mezclas para bizcochos y barras de cereales

Bizcocho relleno con manjar y cobertura sabor chocolate 


\section{Jugos endulzados y bebidas energéticas}

Bebida de durazno

*Organización Panamericana de la Salud (OPS). Organización Mundial de la Salud (OMS). Modelo de perfil de nutrientes de la Organización Panamericana de la salud. 2016.

Es relevante mencionar que, al usar este instrumento, también se pudo apreciar que los estudiantes tienen patrones de compra determinados, ya que mencionaron de 1 a 5 productos como máximo en cada listado realizado. Esto también responde a que tienen gustos definidos y consolidados. Son muy pocos los estudiantes que diversifican su consumo de productos en este tipo de máquinas expendedoras.

El consumo de productos ultraprocesados se debe principalmente al sabor y la cercanía o accesibilidad a las máquinas expendedoras. Los estudiantes mencionaron que aún así conozcan que estos productos son dañinos para la salud, los seguirán consumiendo debido al buen sabor que estos productos presentan. Por otro lado, algunos estudiantes indicaron que no ven ninguna consecuencia hacia su salud en ese momento, por lo que consideran que si no se consume en exceso no les hace daño.

"Porque me gustan los productos ultraprocesados. En realidad, me gusta el sabor, si me hace bien o mal como que no me importa".

(Estudiante de Administración y marketing, 21 años)

"A obvio, sé que son malos, pero igual lo seguiría comiendo porque son ricos".

(Estudiante de Psicología, 21 años)

El estado de ánimo como el estrés, la ansiedad, la tristeza y la depresión influyen en la decisión de compra de los estudiantes. La mayoría indicó que al tener una de estas emociones, la compra de estos productos se altera, ya que utilizan este tipo de alimentos como una forma para sentirse mejor y los productos más consumidos son los dulces como los chocolates. Sin embargo, la cantidad del consumo dependerá de cómo estas emociones 
se expresen en cada persona, debido a que algunos lo manifiestan comiendo menos y otros comiendo más.

"Si, ósea yo soy al revés cuando estoy feliz como más y cuando estoy triste como menos, pero si pienso que el estado de ánimo si va a influir en mi compra”.

(Estudiante de Medicina, 18 años)

"Si, sí el estrés sí, definitivamente. Te hace consumir todo este tipo de productos como galletas de chocolate y esto para que la persona se sienta mejor"

(Estudiante de Administración y negocios del deporte, 19 años)

"Yo soy una persona un poco ansiosa entonces para liberar mi ansiedad a veces como de más, a veces es sin la necesidad de tener hambre, es decir inconscientemente”.

(Estudiante de Medicina, 23 años)

Asimismo, el periodo menstrual en las estudiantes mujeres causa una variación en el consumo de productos ultraprocesados. La mitad de las entrevistadas en el grupo focal indicaron que suelen comprar una mayor cantidad de estos productos, porque en esas temporadas sienten la necesidad de comer más de lo usual.

"Si, cuando estoy con mi periodo, me descontrolo con la plata y la máquina. Se me da por comprar mil chocolates, si fuera por mí me lo compro todo".

(Estudiante de Medicina, 20 años)

Por otra parte, un aspecto importante en este tipo de productos es el etiquetado o la información nutricional que presentan. Con respecto a ello, la mayoría de los estudiantes, son conscientes que este tipo de productos pueden ser dañinos para su salud. Sin embargo, solo una minoría lee el etiquetado nutricional. Algunos de los problemas encontrados ante la falta de lectura de este apartado era la terminología y el lenguaje utilizado, puesto que los estudiantes no logran entender y no se sienten familiarizados con estos términos. Por ello, piensan que es dirigido solo hacia el personal de salud y no precisamente a ellos, quizás esto genere que no exista una cultura de lectura del etiquetado nutricional. 
El diseño, también forma parte de la problemática, ya que la mayoría de los empaques presentan muchos números y letras pequeñas, generando confusiones entre los lectores debido a la saturación de información en un espacio reducido. Asimismo, esto se puede deber a que no saben interpretar las unidades para medir las cantidades del empaque (g, mg, \%), las siglas o abreviaturas y el tamaño de porción comparada con el tamaño del empaque descrita en la tabla nutricional. No obstante, se encontró que aún sin entender completamente la información nutricional, la mayoría de estudiantes refirió que el contenido nutricional del producto puede afectar en su compra, es decir, si el producto contiene un alto contenido en calorías, azúcar, colorantes o saborizantes preferirían no comprarlo. Sin embargo, lo que mencionan es contradictorio y no se cumple con su accionar, ya que como se ha detallado anteriormente la mayoría de ellos le brindan más importancia al sabor o al gusto y compran el producto.

"La información en la etiqueta es confusa, no es clara. A veces usan mucho tecnicismo y no se logra entender bien lo que te trata de informar".

(Estudiante de Ingeniería Civil, 21 años)

"Los términos que a veces ponen son muy técnicos, que a la gente como ustedes, que estudian nutrición, sí deben de entenderlo. Pero gente que realmente no está familiarizada con esos términos lo desconoce".

(Estudiante de Psicología, 21 años)

La mayoría de estudiantes mencionaron que se debería hacer uso de palabras sencillas y no tecnicismos al hacer referencia a los macro y micronutrientes o en todo caso sí se utilizan, describir en alguna parte su significado para que ayude a la interpretación. También algunos estudiantes mencionaron que así entiendan la tabla nutricional no saben cómo les afectaría a su organismo. Por eso, indicaron que se debería poner en la etiqueta las consecuencias de consumir en exceso el producto. Cabe resaltar que una minoría de entrevistados mencionaron que más que hacer un cambio a la etiqueta, se debe enseñar o se deben realizar campañas de concientización sobre la lectura e interpretación del etiquetado nutricional, dado que lo que más les interesa saber es si están comiendo en exceso algún nutriente, como grasa o azúcar, que pueda afectar a su organismo. 
“Creo que, no sé, tendría que haber una política de concientización y digamos que las marcas deberían informarnos que significa cada palabrita ¿no? Porque está bien nos están informando, pero como que es una información limitada ya que, no entiendes lo que en verdad te quieran decir".

(Estudiante de Ingeniería Civil, 22 años)

\subsection{Uso de máquinas expendedoras}

En cuanto al uso de las máquinas expendedoras, se da principalmente por la facilidad, cercanía y rapidez para adquirir los productos, debido a que la acción de comprar depende en gran medida del tiempo y de la sensación de hambre o antojo que sientan los estudiantes universitarios. La mayoría de ellos indicaron que suelen comprar los productos de las máquinas, en promedio entre 3 y 4 veces a la semana, siendo la frecuencia máxima de 3 a 4 veces por día. Lo cual va a depender de los horarios que tengan en la universidad, es decir los días que asisten al campus o tienen clases todo el día tienden a comprar más veces en estas máquinas, por tanto, existe mayor consumo de estos productos.

“Ósea también como frutas, pero está más lejos, por la cercanía más que nada, ósea estoy en el pabellón, estoy a menos de 10 metros de la máquina expendedora. Prefiero ir a un lugar un poco más cercano a ir un lugar un poco más lejano”.

(Estudiante de Medicina, 23 años)

“¿Cuántas veces al día? Haber unas 4, depende de cuánto tiempo estoy en la universidad. Sí estoy simplemente en la mañana puede ser una sola vez entre clase y clase pero, sí estoy todo el día sí unas 4".

(Estudiante de Psicología de 21 años)

La compra en las máquinas expendedoras se da cuando tienen algún receso durante clases o cuando no les alcanza el tiempo para tomar desayuno u otra comida principal del día. Debido a que la mayoría de estudiantes suelen tener tiempos cortos entre clases o clases de varias horas que ocupan el tiempo que se debería destinar para el consumo de sus comidas 
principales. Lo cual genera el reemplazo por dichos productos ultraprocesados. Sin embargo, para una minoría de estudiantes les resulta imposible el reemplazo de sus comidas principales, puesto que se encuentran dentro de un régimen dietético por motivos deportivos, salud o estética. En algunos casos comprar productos de las máquinas expendedoras por las tardes se ha convertido en algo rutinario. Adicional a ello, otra de las razones mencionadas era el antojo creado por la compra de un producto por sus compañeros y/o amigos. Lo cual demuestra que este tipo de acciones puede verse influenciada por el deseo o antojo al ver comprar a otro.

"Más en la noche o muy temprano cuando tengo clases 7 de la mañana, digamos ahí compro algo rápido porque no como, no tomo desayuno o cuando tengo clases hasta muy tarde y entonces me da hambre como que a las 7, 8 de la noche me compro algo..."

(Estudiante de Medicina de 23 años)

"Sí, no me siento orgulloso de decir eso, pero muchas veces sí reemplazo mis comidas, por lo mismo de que no tengo hueco en las horarios y por ejemplo, estudio desde las 11 am hasta las 3 pm y en ese lapso a las justas me doy un tiempo para ir a comprar a la dispensadora nada más...”

(Estudiante de Ingeniería Civil, 22 años)

"No, no lo hago. No reemplazo mis comidas principales. Porque no podría comparar el beneficio que me da un plato de comida con un producto golosinario".

(Estudiante de Arquitectura, 21 años)

El precio es también otro de los factores decisivos en el proceso de compra. Los estudiantes refirieron gastar entre un sol a cinco soles aproximadamente por compra en las máquinas expendedoras. Ellos indicaron no tener problema en invertir esta cantidad de dinero en este tipo de productos, debido a que consideran que los precios que tienen en las máquinas son similares a los precios de una tienda fuera de la universidad, por lo que la mayoría considera 
que ahorran tiempo comprando en las máquinas que se encuentran cercanas. Además de no tener que esperar para ser atendidos y obtener sus alimentos. Por otro lado, consideran que los precios son más accesibles en comparación con las cafeterías y máquinas expendedoras saludables que se encuentran en el mismo campus. Asimismo, la mayoría de estudiantes, manifestaron que al no tener dinero para comprar dichos productos, solo optaban por no consumirlos, ya que algunos de ellos solo llevan una cantidad calculada de dinero. Sin embargo, ciertos estudiantes mencionaron tener la necesidad de siempre prestarse dinero de otros compañeros para poder comprar estos productos.

Por otro lado, la publicidad, es asociada con la cantidad de máquinas expendedoras y la ubicación de las mismas dentro del campus universitario. La mayoría de estudiantes refieren que al salir de clases o de algún ambiente de la universidad observan estas máquinas sintiendo antojo por comprar algún producto. Ellos mencionan que todas las máquinas se encuentran en puntos estratégicos y presentan los mismos productos, por lo que observarlos todos los días es una forma indirecta de publicidad. Con respecto a la publicidad convencional como carteles o comerciales, no es influyente a la hora de la compra, porque no suelen encontrarlos dentro de los pabellones de la universidad u observarlos en las calles aledañas.

"Las máquinas expendedoras se encuentran en la mayoría de pabellones, se encuentran dónde están todos los salones; además que si de repente tienes clases seguidas no te da tiempo para ir hasta la cafetería, hacer cola y comprar algo. Por eso usas la máquina expendedora, es más rápido”.

(Estudiante de Terapia Física, 19 años)

"Yo creo que sí influye la publicidad, porque como te digo hay varias máquinas en casi en todos los lugares, en todos los pabellones, entonces supongo que si es que lo tienes cerca, si es que lo tienes más a la vista, es más probable que lo compres...".

(Estudiante de Medicina, 23 años) 
"No creo, que influencie la publicidad, a mí en particular no me suma ni me resta. No sé a los demás, pero creo que no. Porque hace un montón de tiempo que no veo un comercial de galletas, creo que no".

(Estudiante de Administración y Negocios Internacionales, 20 años)

Con respecto a la compra de productos expendidos en la máquina, se pudo evidenciar que existe una fidelización del cliente, puesto que algunos productos se encuentran posicionados en la mente de los estudiantes, esto se confirma al encontrar que la gran mayoría se acercan a las máquinas expendedoras sabiendo el producto que van a adquirir.

Además, los productos expendidos en este tipo de máquinas son percibidos como de bajo valor nutricional, ya que presentan gran cantidad de grasa, azúcar y sodio. Estas características son reconocidas por los estudiantes universitarios, a pesar de que estos productos carezcan de algún tipo de advertencia nutricional en su etiqueta.

"La mayoría son de baja calidad, porque prácticamente son grasas y grasa saturada".

(Estudiante de Arquitectura, 22 años)

Asimismo, la minoría mencionó que los productos adquiridos en estas máquinas pueden llegar a ser regulares, es decir ni malos ni buenos, ya que existen algunos productos integrales en venta.

"Bueno en su mayoría son malos. Una que otra galleta que es como la que venden en la máquina saludable, que son integrales, esas me parecen más o menos sanas”.

(Estudiante de Administración y negocios internacionales, 22 años) 
Por último, la elección de un producto de la máquina expendedora va a depender del sabor, preferencias y del precio que estos pueden llegar a tener. La mayoría mencionó que aunque existiera una forma de proveer alimentos saludables en las máquinas, sí es que estos no cumplen con lo anterior, no van a ser consumidos por los estudiantes universitarios.

"Compraría fruta en la máquina, pero depende de la fruta, la que más me gusta es la mandarina. También depende del precio ¿no? Si te conviene comprarlo en un mercado o un supermercado, o comprarlo en las máquinas expendedoras, porque obviamente ahí son más caras..."

(Estudiante de Ingeniería Civil, 18 años)

\subsection{Conocimiento de alimentación saludable}

Los horarios de la universidad, la carga académica y la disponibilidad de tiempo van a influir en el tipo de alimentación que posee cada universitario. La mayoría de estudiantes calificaron su alimentación como "no balanceada, "desequilibrada", "malísima o "pésima". Para los estudiantes una dieta no balanceada es aquella compuesta por alimentos como: galletas o dulces que brindan azúcar o grasa en exceso y por la escasa inclusión de verduras. Asimismo, asociaban el no respetar sus horarios de comida con una alimentación no balanceada, malísima o pésima.

"Creo que mi alimentación es así más por la vida universitaria, ya que comes lo que encuentras, porque a veces, los horarios no coinciden y no te dejan tiempo para tu almuerzo y desayuno. Ahí ya tú buscas solo la comida que tienes a tu alcance”.

(Estudiante de Ingeniería Civil, 21 años)

“Creo que mi alimentación no es balanceada, porque más como golosinas, galletas. Como muy pocas verduras, busco, cosas rápidas para tener más tiempo para estudiar o para venir a clases”.

(Estudiante Administración y negocios internacionales, 22 años) 
"Considero mi alimentación como no balanceada porque no siento que coma a mis horas, los desayunos, por ejemplo, lo puedo tomar muy temprano o muy tarde, bien a las 7 de la mañana o 6:30 o bien a las 10- 11 y el almuerzo igual, muy variado, depende mucho del horario de la universidad".

(Estudiante de Medicina, 23 años)

“Mi alimentación era demasiado desequilibrada... Y ¿De qué forma? Por ejemplo, comía azúcar ósea para los jugos, comía los que son galletas, dulces, caramelos”.

(Estudiante de Psicología, 21 años)

La alimentación normal o buena es considerada por la mayoría estudiantes cuando consumen sus comidas principales en las horas correspondientes e incluyen porciones de verduras dentro de sus comidas. Inclusive, manifestaban que no adquirir y no consumir en demasía productos ultraprocesados, hacían que califiquen su alimentación como normal o buena. También es fundamental mencionar que se evidenció que la minoría de alumnos califican su alimentación como saludable, ya que considera que la alimentación que llevan les asegura los "nutrientes" importantes para su organismo y su correcto funcionamiento. En otras palabras, el hecho de dar mayor prioridad al aporte nutricional que al sabor o al gusto es una forma de considerar su alimentación como saludable.

"Mi alimentación es normal porque como tres veces al día, y a veces compro en las máquinas expendedoras y no como en demasía”.

(Estudiante de Administración de Negocios, 20 años)

“ ¿Mi alimentación? Saludable, porque siempre priorizo los nutrientes antes de que el sabor, antes de por ejemplo, darme un gusto en consumir galletas y esas cosas, priorizo alimentarme de verdad, es decir comida casera".

(Estudiante de Psicología, 23 años)

Todos los estudiantes consideran que una alimentación saludable trae consigo una mejora del estado anímico y apariencia física, así como la prevención de enfermedades como el cáncer, obesidad, enfermedades cardiovasculares y digestivas. También, la mayoría de ellos 
manifiestan que esto traería consigo un sistema inmunológico adecuado, el cual evitaría cualquier infección por virus o bacterias.

"Los beneficios de una alimentación saludable sería la prevención de enfermedades. También que te ayuda a cambiar tu estado físico, no hace que envejezcas tan rápido”.

(Estudiante de Medicina, 20 años)

"Los beneficios serían la prevención de enfermedades, también influye en sus estados de ánimo, en cuanto, a cómo te sientes, si tiene ganas de hacer algo, o si te sientes cansado te da energía. Te ayuda a la regeneración de huesos, músculos también”.

(Estudiante de Terapia Físico, 18 años)

“¿Una alimentación saludable? pues que estés menos expuesto a contraer algún virus ósea gripe, te enfermas mucho menos, tienes mayor defensas contra alguna u otra bacteria”.

(Estudiante de Administración y negocios del deporte, 22 años)

En cuanto a los productos saludables, todos los estudiantes consideran que aportan los "nutrientes" necesarios, entre ellos, los que mencionan son: proteínas, carbohidratos, vitaminas, omega 3 y 6 , para un buen desarrollo y un correcto balance nutricional. Además, opinan que un producto saludable es aquel que no contiene una alta cantidad de sodio, grasa o azúcar. De igual manera, el que no tengan una gran cantidad de aditivos o colorantes, es decir que sean lo más cercano a lo natural, también hace considerarlos como un producto saludable. Asimismo, indicaron que son productos que no hacen daño a la salud y que, por lo contrario, ayudan al organismo.

"Los productos saludables suelen ser los que mayor parte de su proporción contribuyen al desarrollo o digamos a la energía, a la producción de un ser humano”.

(Estudiante de Ingeniería, 22 años)

“¿Los alimentos saludables?, bueno creo que son los que normalmente uno puede consumir, ósea lo que tu cuerpo normalmente te pide para consumir ¿no? que no te haga tanto daño a tu salud que no sea un producto tan artificial, tan procesado.

(Estudiante de Administración y negocios internacionales, 19 años) 
"Creo los productos saludables, son esos que tienen baja grasa y azúcar..."

(Estudiante de medicina, 23 años)

"Los productos saludables son los que te brindan nutrientes, proteinas, vitaminas, carbohidratos adecuados, que no contengan un nivel de sodio muy alto ni tampoco muy bajo, que tenga omega 3 y 6 . Un producto que te brinde todas esas cosas es bien difícil y lo que realmente hay en las máquinas son puro carbohidrato”.

(Estudiante de psicología, 23 años)

Con respecto a los conocimientos sobre productos no saludables, la mayoría de estudiantes lo definen como aquellos que causan daño a la salud, que no nutren el organismo y que puede ser todo aquel alimento que contengan en la mayor parte de su composición; grasa y azúcar y por ende, brinde más calorías. Incluso, manifiestan que estos productos contienen muchas sustancias químicas, conservantes y preservantes que perjudicarían la salud del consumidor y solo sirve para saciar el hambre que sientan en el momento.

"Pues serán todo lo contrario a los productos saludables, estos productos no saludables son los que ponen en peligro mi salud"

(Estudiante de Medicina, 23 años)

"Los productos no saludables son los que tienen demasiadas calorías o demasiada grasa. Por ejemplo, las papas fritas. Las galletas morochas, obviamente son productos no saludables, pero es un dulce, es un gusto"

(Estudiante de Administración y Negocios internacionales, 20 años)

"Pues creo que los productos no saludables son los que tienen mucha sal, los que tienen mucha azúcar y gran cantidad de grasa o ingredientes artificiales"

(Estudiante de Medicina, 23 años)

"Pues los productos no saludables serán todo lo que tengan preservantes, colorantes, que tenga químicos que realmente no sabes pronunciar (risas), todo lo que pueda ser guardado por más de dos años o por más de un año” 
Según la percepción sobre productos ultraprocesados la mayoría de los estudiantes manifestaron que las características tales como: durabilidad, alto contenido de aditivos o "no natural" se asocian con el término ultraprocesados, dado que, para la mayoría de ellos, los ingredientes o el contenido de estos productos es en su totalidad químicos. Mientras que los productos procesados son reconocidos como aquellos que en su composición tienen aún la materia prima, y su consumo presenta una menor peligrosidad para el organismo. En cuanto al conocimiento sobre estos dos términos, la mayoría de estudiantes tienen cierta noción sobre ellos. Asocian ultraprocesado, al producto que pasa por más procesos industriales que uno procesado, y que estos a su vez dañan la salud, causando diversas enfermedades. Mientras que la minoría de estudiantes, no conocía ni había escuchado el término ultraprocesado.

"La verdad me imagino que ultraprocesado es algo que no tiene absolutamente nada natural, que ya todo lo que tiene es falso."

(Estudiante de Terapia Física, 19 años)

"No, no sé, no tengo una idea clara de que son los productos ultraprocesados, ¿no?, me imagino que debe ser esto algo así que ya es sobrenatural, de que te va a durar. Le metes un mordisco y dentro de 3 días regresas y sigue igual, intacto, no sé nunca he escuchado ese término."

(Estudiante de Psicología, 23 años)

"Creo que los productos ultraprocesados son aquellos que tienen muchos, muchos químicos."

(Estudiante de Administración y negocios internacionales, 19 años)

“ ¿Productos ultraprocesados? supongo que son productos que, por ejemplo, tienen su fecha de vencimiento muy larga, que duran."

(Estudiante de Arquitectura, 22 años) 
"No, la verdad que no sé qué significa eso. Es que no conozco que son los productos ultraprocesados, en verdad no sé qué son."

(Estudiante de Gestión Minera, 22 años)

\section{DISCUSIÓN}

El presente estudio, tuvo como uno de sus objetivos identificar los productos ultraprocesados de mayor consumo en las máquinas expendedoras, encontrando que la mayoría de los estudiantes adquieren en mayor frecuencia productos como hojuelas de papas fritas con sabor picante, goma de mascar sin azúcar, galletas de vainilla bañadas parcialmente en cobertura sabor a chocolate, caramelos refrescantes y maní salado, los cuales se encuentran en los cinco primeros lugares de los más consumidos. En un estudio realizado en Australia, se evaluó la disponibilidad y el valor nutricional de los alimentos en las máquinas expendedoras de cinco campus universitarios. Además, se examinaron los puntos de vista de los usuarios a través de encuestas a los estudiantes y al personal de los campus evaluados, encontrándose que el producto comprado con mayor frecuencia fueron las papas fritas. Asimismo, se determinó que el $93 \%$ de los productos encontrados fueron considerados como menos saludable y que el mayor porcentaje de estos productos pertenecían a los chips, chocolates, dulces y galletas dulces, en orden descendente respectivamente (35). Además, en otro estudio similar realizado también en el país de Australia, se pudo observar que los resultados son consistentes con los encontrados en la presente investigación. Este estudio identificó un total de 61 máquinas expendedoras de una universidad urbana, donde los productos ultraprocesados más consumidos por parte de los universitarios fueron las papas fritas o chips, seguido por chocolates, frutas o frutos secos. Además, se concluyó que las máquinas expendedoras comercializan y venden alimentos y bebidas consideradas como menos saludables a los estudiantes universitarios (36). Este frecuente consumo de productos ultraprocesados encontrado en los estudiantes han sido asociados significativamente con un mayor riesgo de sobrepeso y obesidad. Tal como se demuestra en un estudio de la universidad de Navarra en España, donde se encontró la asociación entre el consumo de productos ultraprocesados y el riesgo de contraer esta condición nutricional en universitarios (37). 
Un punto importante ante los productos más consumidos fue la fidelización de los estudiantes por ciertas marcas, dado que al conocerlos con anterioridad eran señal de calidad. Esto mismo se observó en un estudio cualitativo donde ciertos entrevistados indicaron inclinar su preferencia hacia ciertas marcas de productos como parte de su tradición de compra (38). Por otra parte, los estudiantes relacionaron la ubicación de las máquinas expendedoras como método de publicidad, ya que al ver estos productos por diversos lugares dentro campus universitario crea el antojo de ellos. De por sí, las envolturas tienen un vínculo estrecho con la publicidad. Las empresas lo utilizan para aumentar la cantidad de ventas en el producto y no para la educación de los consumidores hacia una alimentación más saludable (39). Es por ello, que quizás al ver reiteradamente estos productos con envoltorios tan llamativos en distintos puntos estratégicos donde las máquinas expendedoras se encuentran y sabiendo que tienen sabores agradables, los estudiantes optan por esta clase de productos. La Organización Panamericana de la Salud, también menciona dentro del plan de reducción del consumo de productos ultraprocesados que se debe restringir cualquier tipo de mercadotecnia, ya que esta representa una influencia grande para la compra de estos productos en el consumidor (6).

Otro de nuestros objetivos era identificar los motivos de consumo de productos ultraprocesados en las máquinas expendedoras en estudiantes. Hallando que los motivos para el consumo de estos productos eran principalmente el sabor, precio, horario académico, estado de ánimo y la cercanía de dichas máquinas, lo cual se relaciona con la facilidad y la rapidez para obtener los productos, debido a que no disponen de mucho tiempo para su alimentación entre clases. Los resultados detallados son similares con diversos estudios. Según las opiniones de los participantes de un estudio en Australia, la compra de esos productos en las máquinas expendedoras fueron debido al hambre y la conveniencia, además, la elección de los alimentos fue principalmente por el sabor, precio y el hambre (35). Igualmente, una investigación realizada en Reino Unido en estudiantes universitarios con sobrepeso u obesidad se encontró que la razón más común para consumir snacks no saludables era debido a que, estos se veían y olían muy tentadores, seguido de la sensación de hambre (40). Aunque en nuestro estudio la población fue de estudiantes en general, sin tomar en cuenta el índice de masa corporal (IMC), los resultados fueron similares, encontrando que los estudiantes tenían preferencia por este tipo de productos, por el sabor que les brinda. Asimismo, una investigación en universitarios de Bangladesh, indicaron que 
la mayoría de ellos consumían productos de bajo valor nutricional debido a los precios, la disponibilidad y el entorno físico que tenían. Además, menciona que la elección de alimentos es afectada por el sabor de los mismos (41). Es por ello que al encontrar máquinas expendedoras en diversos lugares dentro del campus puede afectar negativamente las preferencias de consumo de los estudiantes, lo que podría conducir al sobrepeso y obesidad.

Otro de los motivos encontrados es el horario académico, ya que les deja poco tiempo para el consumo de sus dos primeras comidas principales. Lo cual se asemeja con un estudio cualitativo en estudiantes de una universidad de Chile donde se pudo evidenciar que no percibían consumir una dieta saludable, ya que la carga académica ejerce una influencia negativa en una de sus principales comidas como el almuerzo. Esto debido a que, no tienen un tiempo establecido para consumir dicha comida del día. Inclusive, mencionan explícitamente que las principales causas de no consumir un almuerzo saludable eran los horarios restringidos que tenían (42). Asimismo, en otro estudio cualitativo de una universidad de Emiratos Árabes Unidos, se halló que una de las razones para que los estudiantes compren en las máquinas expendedoras del campus eran los horarios ocupados que tenían y la accesibilidad que tienen hacia ellas. Además, indicaron que para la elección del alimento dentro de dichas máquinas influía: la aceptación de los compañeros y las preferencias personales (43). Estos mismos horarios restringidos hacen que los estudiantes entrevistados en nuestro estudio consuman productos no saludables de las máquinas expendedoras.

Otra razón que encontramos para que los estudiantes consuman productos ultraprocesados fue el factor emocional. El estado de ánimo, tales como el estrés, la ansiedad, tristeza, y la depresión son las situaciones que influyen para que los estudiantes consuman dichos productos. En un estudio realizado en Arabia Saudita, cuyo objetivo principal fue explorar las alteraciones asociadas al estrés en sus hábitos alimenticios en estudiantes universitarios, mostró que esta emoción conlleva a los adultos jóvenes prefieran y consuman "comida chatarra, comidas rápidas" y "refrigerios" (19), lo cual coincide con una de las emociones descritas por los estudiantes en nuestra investigación.

Aunque el fondo de nuestro estudio no era explorar el conocimiento de los estudiantes ante el etiquetado nutricional, es interesante saber cómo era visto antes de la implementación del 
etiquetado octogonal. En este caso se encontró que los estudiantes no leen este apartado y a su vez mencionan no comprender la información mostrada. Lo anterior concuerda con lo encontrado en un estudio mixto en personas desde 19 años hasta mayores de 40 años, donde se vio que la mayoría de ellos no leía esta información y el mayor desconocimiento se encontraba en la identificación e interpretación de los porcentajes expuestos y el tamaño de porción del producto. Este escaso conocimiento era insuficiente para guiar una correcta elección de productos. Solo algunas personas dentro de este estudio indicaron entender el etiquetado y se caracterizaron por padecer una enfermedad (38). El estudio descrito anteriormente y nuestros resultados demuestran que era una necesidad el cambio de etiquetado para brindar información de fácil lectura y comprensión.

Otro hallazgo que se desprende de nuestro estudio es que a la mayoría de estudiantes presentaba una idea vaga de lo que entendían por alimento ultraprocesado que coincide con un estudio cualitativo realizado en una universidad de México. En donde se pudo evidenciar que del mismo modo que los universitarios mostraron confusión entre la clasificación de alimentos procesados y ultraprocesados (20). También se pudo encontrar en nuestro estudio, que la mayoría conocía los efectos negativos que tenía el consumo de estos productos para su salud. Ello se puede relacionar con los resultados de un estudio en la universidad de Bogotá donde indicaron que, aunque los estudiantes tenían conocimiento acerca de lo adecuado para su alimentación no lo realizan así por distintas barreras que marcan los hábitos y las elecciones que ellos puedan tener (44).

\section{LIMITACIONES Y FORTALEZAS}

La limitación de nuestro estudio radica en que los resultados obtenidos no se pueden generalizar a ningún otro campus de la universidad, sino que sólo representa a la población analizada.

Por otro lado, una de las fortalezas en nuestro estudio es que profundiza los motivos de compra de productos ultraprocesados que tienen la mayoría de estudiantes universitarios, lo cual ayudaría a definir estrategias a nivel universitario para evitar el consumo de estos productos. Otra fortaleza es que va a proveer información acerca de la situación en la compra de productos ultraprocesados dentro de un centro de estudios y con ello, poder tomar acciones que modifiquen el ambiente alimentario obesogénico en el campus. Asimismo, es 
uno de los pocos estudios en el país que busca explorar los motivos de consumo de productos ultraprocesados en máquinas expendedoras dentro de un lugar con mucha concurrencia como lo es una universidad.

\section{CONCLUSIÓN}

En conclusión, este estudio tuvo como objetivo general explorar los motivos de consumo de productos ultraprocesados en máquinas expendedoras de una universidad privada encontrando que el sabor, precio, horario académico, estado de ánimo y la cercanía de dichas máquinas, lo cual se relaciona con la facilidad y la rapidez para obtener estos productos. Sin embargo, es necesario precisar que los estudiantes conocían que estos productos eran dañinos para su salud, pero aun así los seguían consumiendo por los motivos descritos anteriormente.

\section{RECOMENDACIONES}

A partir de este estudio se abren puertas a investigaciones más complejas que integren una metodología mixta para tener una perspectiva más amplia de lo que sucede en otras zonas del país sobre el consumo de productos ultraprocesados. Además de contar con una muestra más representativa a una población. Por otro lado, se recomienda que las autoridades académicas tomen en cuenta los horarios de las comidas principales de los alumnos para evitar su reemplazo por productos ultraprocesados. Asimismo, es importante que las estrategias y promoción en salud y nutrición sean constantes y abarquen la disminución de máquinas expendedoras, el cambio de ubicación dentro del campus o el reemplazo de productos ultraprocesados por alimentos saludables pero con precios accesibles. De esa forma al reducir la disponibilidad de los productos ultraprocesados se podría disminuir el consumo de estos productos. 


\section{REFERENCIAS BIBLIOGRÁFICAS}

1. Cuevas García-Dorado S, Cornselsen L, Smith R, Walls H. Economic globalization, nutrition and health: a review of quantitative evidence. Global Health. 2019 Feb 20;15(1):15.

2. De la Cruz Sanchez E. La transición nutricional: Abordaje desde de las políticas públicas en América Latina. Universidad Pedagógica Experimental Libertador. 2016.

3. INEI. La transición Nutricional en el Perú. 2007.

4. Knorr D, Khoo CSH, Augustin MA. Food for an Urban Planet: Challenges and Research Opportunities. Front Nutr. 2018 Jan 19; 4:73.

5. Popkin BM. Nutrition Transition and the Global Diabetes Epidemic. Curr Diab Rep. 2015;15(9):64.

6. Organización Panamericana de Salud (OPS). Organización Mundial de la Salud (OMS). Alimentos y bebidas ultraprocesados en América Latina: tendencias, efecto sobre la obesidad e implicaciones para las políticas públicas. 2015.

7. Organización Panamericana de Salud (OPS). Organización Mundial de la Salud (OMS). Alimentos y bebidas ultraprocesados en América Latina: ventas, fuentes, perfiles de nutrientes e implicaciones normativas. 2019.

8. Asociación Nacional de Distribuidores Automáticos (ANEDA). Estudio de Mercado sobre el comportamiento y satisfacción del consumidor de Máquinas Vending 2016. 2016 .

9. Monroy-Parada, Doris Xiomaraet al. Presencia de máquinas expendedoras de alimentos y bebidas y perfil nutricional de sus productos en los institutos de enseñanza secundaria de la Comunidad de Madrid, 2014-2015. Revista Española de Salud Pública. 2016, 90(00).

10.Martin R. Sánchez C. Suarez M. García R. Blanco M. Et al. Composición nutricional de los alimentos de las vending de edificios públicos universitarios y hospitalarios de Asturias. Aten Primaria. 2019; 52(1): 22-28.

11.Ley de Promoción de Alimentación Saludable para niños, niñas y adolescentes. 2013.

12.Minaker LM. Storey KE. Raine KD. Spence JC. Forbes LE. Et al. Associations between the perceived presence of vending machines and food and beverage logos in schools and adolescents' diet and weight status. Public Health Nutr. 2011 Aug; 14(8):1350-6.

13.Organización Mundial de la Salud (OMS). Enfermedades No Transmisibles. 2018. 
14.Organización Panamericana de la Salud (OPS). Organización mundial de la Salud (OMS). Enfermedades no transmisibles y factores de riesgo. [Internet] 2020.

15.Organización Panamericana de la Salud (OPS) y la Organización Mundial de la Salud (OMS). Factores de riesgo de las enfermedades no transmisibles en la Región de las Américas: Consideraciones para fortalecer la capacidad regulatoria. 2016.

16.Organización Mundial de la Salud (OMS). Sobrepeso y obesidad. 2018.

17.INEI. Perú: Enfermedades No Transmisibles y Transmisibles, 2019. 2020.

18.Almogbel E. Aladhadh AM. Almotyri BH. Alhumaid AF. Rasheed N. Stress Associated Alterations in Dietary Behaviours of Undergraduate Students of Qassim University, Saudi Arabia. Open Access Maced J Med Sci. 2019 Jul 10;7(13):2182-2188.

19.Shaban L. Alkazemi D. Trends in Fast-food Consumption among Kuwaiti Youth. Int. J Prev Med. 2019 Apr 17; 10:44.

20.Nieto C, et al. Perception about the consumption of processed foods and ultra-processed products in postgraduate students in Mexico City. Journal of Behavior, Health \& Social Issues México. 2017.

21. Njike, V. Y., Smith, T. M., Shuval, O., Shuval, K., Edshteyn, I., Kalantari, V., \& Yaroch, A. L. (2016). Snack Food, Satiety, and Weight. Advances in nutrition .7(5), 866-878.

22. Ministerio del Perú. Un gordo problema: Sobrepeso y Obesidad en el Perú. 2012.

23.Matthews MA, Horacek TM. Vending machine assessment methodology. A systematic review. Appetite. 2015;90:176-186.

24.Park H. Papadaki A. Nutritional value of foods sold in vending machines in a UK University: Formative, cross-sectional research to inform an environmental intervention. Appetite. 2016 Jan 1; 96: 517-525.

25.Salgado A. Investigación cualitativa: Diseños, evaluación del rigor metodológico y retos. Liberabit. 2007 Set 21. 13(13): 71-78.

26.Martínez-Salgado C. El muestreo en investigación cualitativa: principios básicos y algunas controversias. Cienc. Saúde coletiva. 2012; 17(3):613-619.

27.Instituto de Nutrición de Centro América y Panamá (INCAP). Organización Panamericana de la Salud (OPS). Seguridad Alimentaria y Nutricional a nivel Local. Manual de Investigación Cualitativa. 1999.

28.Callejo J. Observación, entrevista y grupo de discusión: El silencio de tres prácticas de investigación. Rev Esp Salud Pública 2002; 76: 409-422. 
29.Alzás, Teresa, et al. Revisión metodológica de la triangulación como estrategia de investigación. Atas - Investigação Qualitativa em Educação. 2016.

30.Ministerio de Salud (MINSA). Semana de lucha contra la obesidad. 2017.

31.Organización Mundial de la Salud. Informe de la Comisión Independiente de alto nivel de la OMS sobre Enfermedades no Transmisibles: Es hora de actuar. Ginebra: 2018.

32.United Nations System Standing Committee on Nutrition. Enfermedades no transmisibles dietas y nutrición. 2018.

33.Organización de las Naciones Unidas para la Alimentación y la Agricultura. Organización Panamericana de la Salud. Organización Mundial de la Salud. Politicas y programas alimentarios para prevenir el sobrepeso y la obesidad. 2018.

34.Organización Panamericana de la Salud (OPS). Organización Mundial de la Salud (OMS). Modelo de perfil de nutrientes de la Organización Panamericana de la salud. 2016.

35.Ng KW. Sangster J. Priestly J. Assessing the availability, price, nutritional value and consumer views about foods and beverages from vending machines across university campuses in regional New South Wales, Australia. Health Promot J .Austr. 2018 Jan; 30 (1):76-82.

36.Grech, A. Hebden. L. Roy, R. Allman-Farinelli, M. Are products sold in university vending machines nutritionally poor? A food environment audit. Austr. Nutrition \& Dietetics. 2016; 74(2): 185-190.

37.Mendonça RD. Pimenta AM. Gea A, et al. Ultraprocessed food consumption and risk of overweight and obesity: the University of Navarra Follow-Up (SUN) cohort study. Am J Clin Nutr. 2016; 104(5).

38.López-Cano L, Restrepo-Mesa S. Etiquetado nutricional, una mirada desde los consumidores de alimentos. Perspect Nut Hum. 2014; 16(2): 145-158.

39.González Santana S, Romero González J, Tamer Salcido M, Guerra JA. Un estudio del etiquetado nutricional. Culcyt. 2012; 47:39-52

40.Cleobury L, Tapper K. Reasons for eating 'unhealthy' snacks in overweight and obese males and females. J Hum Nutr Diet. 2014 Aug;27(4):333-41.

41.Kabir A, Miah S, Islam A. Factors influencing eating behavior and dietary intake among resident students in a public university in Bangladesh: A qualitative study. PLoS One. $2018 ; 13(6)$. 
42.Doepking C, Zuñiga C, Troncoso C. Qualitative study on college students perceptions on lunch. Medwave. 2013; 13(2): 1-5.

43.Ali HI. Jarrar AH. Abo-El-Enen M. Al Shamsi M. Al Ashqar H. Students' perspectives on promoting healthful food choices from campus vending machines: a qualitative interview study. BMC Public Health. 2015; 15:512.

44.Duarte C. Ramos D. Latorre A. González P. Factores relacionados con las prácticas alimentarias de estudiantes de tres universidades de Bogotá. Revista de Salud Pública. 2015; 17(6): 925-937.

\section{ANEXOS}

14.1 Instrumento de recolección de datos

GUÍA DE PREGUNTAS - ENTREVISTAS A PROFUNDIDAD

- DATOS GENERALES

1. ¿Cuál es tu nombre?

2. ¿Cuál es tu edad?

3. ¿Qué carrera estudias?

4. ¿Cómo percibes que es tu alimentación? ¿Por qué es... o...? Dependiendo de la respuesta del participante.)

\section{- $\quad$ USO DE MÁQUINAS EXPENDEDORAS}

5. ¿Cuándo o en qué horas compras en las máquinas expendedoras? ¿En qué momentos del día adquieres los productos ultraprocesados? ¿Por qué (lo que el participante mencione)? 6. ¿Con qué frecuencia compras productos en las máquinas expendedoras? ¿Cómo así? 7. ¿Qué tipo de productos (galletas, snacks, chocolates) son los que más consumes de las máquinas expendedoras? ¿Por qué?

8. ¿De los que me has mencionado cuáles son los productos que compras con mayor frecuencia? ¿Por qué?

9. ¿Cuántos paquetes de (nombre del producto) consumes al día o a la semana? ¿Por qué?

10. ¿Qué te motiva a comprar los productos de las máquinas expendedoras? ¿Por qué crees que... o... te motiva? 
11. ¿Cuál crees que sea la razón que te incentiva a adquirir productos ultraprocesados?

12. ¿Crees que la publicidad podría estar influenciando a que los estudiantes de la UPC compren estos productos de las máquinas expendedoras? ¿La publicidad influye en tu compra?

13. ¿Cuánto gastas aproximadamente cuando compras en las máquinas expendedoras? ¿Te sale a cuenta comprar en las máquinas que adquirir otro tipo alimento?

14. ¿Reemplazas algunas de tus comidas principales del día por productos de las máquinas expendedoras? (desayuno, almuerzo o cena) ¿Por qué?

15. ¿Qué haces cuando no tienes dinero para comprar algún producto de las máquinas expendedoras?

16. ¿Lees el etiquetado nutricional? ¿Cuál es la información que sueles leer en el etiquetado de producto?

17. ¿Qué opinas de la información presentada? ¿Es clara o confusa? ¿Por qué te parece de esa forma?

18. ¿La información nutricional del producto puede influir en que lo compres? ¿De qué manera la información nutricional del producto influye en tu compra?

19. ¿Entiendes lo que te dice el etiquetado nutricional? ¿Cómo así?

20. ¿Qué crees que te dificulta comprender el etiquetado nutricional?

21. ¿Qué cambios les harían al etiquetado nutricional del alimento para que lo puedas entender mejor? Por ejemplo, ¿Tú cómo lo pondrías?

\section{- $\quad$ PRODUCTOS PROCESADOS Y ULTRAPROCESADOS}

22. ¿Qué entiendes por productos saludables? ¿Qué entiendes por productos no saludables? ¿Por ejemplo, qué productos crees que son saludables y cuáles crees que son no saludables?

23. ¿Qué entiendes por productos industrializados/ procesados / ultraprocesados? ¿Sabes qué son?

24. ¿Sabes qué consecuencias tiene en la salud el consumo de productos ultraprocesados?

25. ¿Sabes que (nombre del producto que más consuma) te hace mal a tu salud? Si lo sabes, ¿Por qué lo consumes?

26. ¿Qué opinión tienes acerca del valor nutricional que tienen los productos que compras en las máquinas expendedoras? 
27. Si en las máquinas expendedoras vendieran frutas ¿Las comprarías? ¿Por qué sí o por qué no?

\section{GUÍA DE PREGUNTAS - GRUPOS FOCALES}

\section{- CONSUMO DE PRODUCTOS ULTRAPROCESADOS EN MÁQUINAS EXPENDEDORAS}

1. ¿Con qué frecuencia consumen productos de las máquinas expendedoras? ¿De qué depende?

2. ¿Qué factores influyen para que decidan comprar sus alimentos en una máquina expendedora?

3. Preg. Para mujeres: ¿Ha habido alguna variación de su consumo cuando están con su periodo menstrual?

4. ¿Qué opinión tienen acerca de los productos que se comercializan en las máquinas expendedoras?

5. ¿Cuáles son los productos que más consumen? ¿Por qué consumen esos productos?

6. ¿Qué cantidad de estos productos consumen por día? ¿Por qué?

7. ¿En qué momentos del día suelen comprar los productos? ¿Por qué?

8. ¿Han reemplazado alguna de sus principales comidas del día (desayuno, almuerzo y cena) por productos de la máquina?

9. ¿Qué características debe tener un producto de la máquina expendedora para que lo consumas?

10. ¿Cuáles crees que son las razones/ motivos para que los estudiantes compren esos productos?

11. ¿Crees que la publicidad podría influenciar en que los alumnos compren productos de las máquinas expendedoras? ¿Por qué? ¿Influye en tu compra?

12. ¿Conocen qué ingredientes contienen estos productos?

13. ¿Cuánto gastan aproximadamente cuando compran en las máquinas expendedoras?

14. ¿Qué opinan sobre el precio de los productos de las máquinas expendedoras? ¿Por qué? ¿Les parecen accesibles los precios?

15. ¿Creen que el estado de ánimo/ estado emocional o humor es un factor que les motiva a la compra de estos productos? ¿Por qué? ¿De qué forma creen que los motiva? (ansiedad, triste, aburrido, alegre, etc) 
16. ¿Qué opinan de la ubicación de las máquinas expendedoras? ¿Creen que pueda influir en la compra de estos productos?

17. ¿Qué es lo primero que observan cuando compran un producto en las máquinas expendedoras? (Explorar si es o no integral, si es o no light) ¿Por qué?

18. ¿Leen el etiquetado nutricional de los productos que adquieren de las máquinas expendedoras? ¿Por qué leen o no leen el etiquetado?

19. ¿Qué lo que suelen leer cuando leen un etiquetado nutricional? ¿Por qué?

20. ¿Comprenden el etiquetado nutricional de los productos que consumes? ¿Por qué sí o no comprenden?

21. ¿Les dificulta comprender el etiquetado nutricional? ¿Qué creen que les dificulta para comprender el etiquetado nutricional? ¿Por qué creen que eso? Explorar

22. ¿Qué cambios les harían al etiquetado nutricional del alimento para que lo puedas entender mejor?

24. ¿La información nutricional del producto puede influir en su compra?

- CONOCIMIENTO SOBRE ALIMENTACIÓN Y PRODUCTOS ULTRAPROCESADOS

25. ¿Qué consideran ustedes que es un snack saludable? ¿Pueden dar un ejemplo?

26. ¿Qué consideran ustedes que es un snack no saludable? ¿Pueden dar un ejemplo?

27. ¿Saben que es un producto procesado y uno ultraprocesado?

28. ¿Qué características debería tener un producto para que ustedes lo consuman?

29. ¿Saben cuáles son los beneficios de una alimentación saludable?

30. ¿Cómo los productos ultraprocesados que consumen afecta a su salud? ¿Por qué? Si la respuesta es "no, ¿Cuánto crees que tendrías que comer para que afecte a tu salud? ¿Crees que en un futuro te puede afectar? 


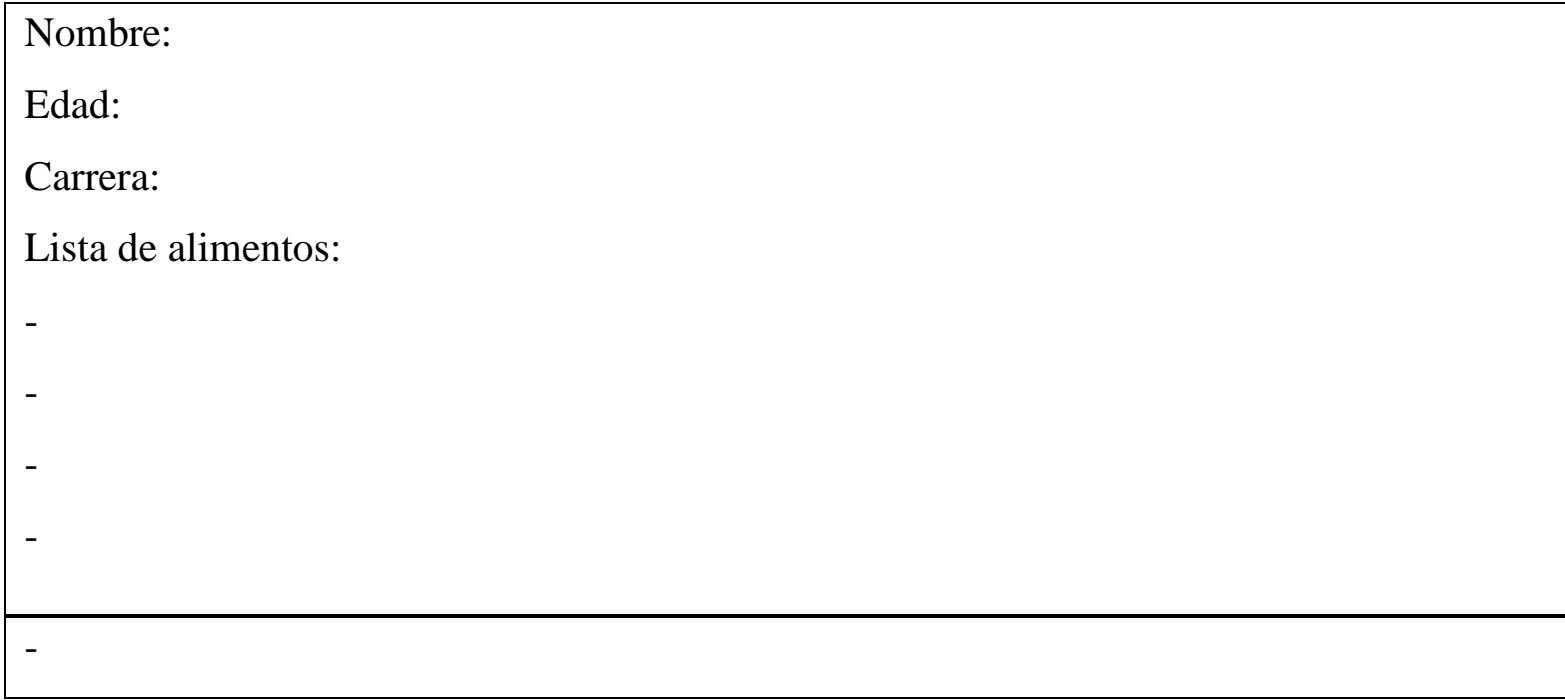

14.2 Consentimiento / asentimiento informado u hoja informativa DOCUMENTO DE CONSENTIMIENTO INFORMADO

Título del trabajo de investigación: Una aproximación cualitativa a los motivos de consumo de productos ultraprocesados de máquinas expendedoras en estudiantes de una universidad privada de Lima, Perú

Nombres de los investigadores:

- $\quad$ Del Aguila Flores, Luz Jasmine

- $\quad$ Nuñez Paucar, Tania Shandini

\section{Introducción:}

A usted se le está invitando a participar de este proyecto de investigación, el cual busca: Explorar los motivos de consumo de productos ultraprocesados en máquinas expendedoras en el periodo 2018-2 en estudiantes de una universidad privada en Lima, Perú.

En el presente documento de consentimiento informado usted encontrará información importante relacionada a: la finalidad del estudio, lo que se le pedirá a usted que haga, los 
riesgos y/o beneficios de su participación, entre otros aspectos que le permitirán decidir si participa o no. Lea detenidamente este documento y siéntase usted con la libertad de hacer las preguntas que considere necesarias.

Sí usted decide participar en esta investigación, deberá colocar su nombre y firmar este documento; se le brindará una copia firmada y fechada.

\section{Justificación del estudio}

La calidad de los productos ultraprocesados que se expende en las máquinas expendedoras se ha evidenciado que son de baja calidad, y que el consumo de ello, puede conllevar al desarrollo de sobrepeso y obesidad. Por esta razón, resulta trascendental conocer cuáles son las razones de los universitarios para adquirir estos productos. Por consiguiente, el objetivo principal de nuestra investigación es explorar los motivos de consumo de los productos ultraprocesados en máquinas expendedoras.

\section{Procedimiento del estudio}

Luego de firmar el consentimiento informado:

- Se aplicará un listado libre de productos ultraprocesados a los alumnos que acudan a las máquinas expendedoras más concurridas de los pabellones de la universidad.

Se realizarán entrevistas a profundidad utilizando una guía de entrevista con preguntas que abarquen el tema a investigar.

Se llevarán a cabo grupos focales en un ambiente cerrado de la Universidad Peruana de Ciencias Aplicadas (UPC).

Ambas entrevistas serán grabadas en audio con ayuda de un Smartphone. 


\section{Riesgos}

La investigación no dispone ningún riesgo al participante.

\section{Beneficios}

No deberá pagar por participar en el estudio

\section{Confidencialidad de la información}

Los datos reportados por el participante serán manejados únicamente por las investigadoras y para el efecto del estudio. Además de ello, no se expondrá ninguna identificación de las personas que decidan participar en esta investigación. Toda información será posteriormente desechada tras concluir con la investigación.

\section{Contacto en caso de consultas o comentarios}

\section{Contacto con los investigadores}

Para comunicarse con los investigadores de este estudio, podrá hacerlo con Luz Jasmine Del Aguila Flores, u201316074@upc.edu.pe o al teléfono 997862999 y Tania Shandini Nuñez Paucar, a través del correo electrónico u201420020@upc.edu.pe o al teléfono 929024484.

\section{Contacto con asesor}

Para contactar al asesor de este estudio Lic. Tula Gloria Uribe Chincha puede escribir al correo electrónico pcnuturi@upc.edu.pe.

\section{Comité de ética}

Sí usted tiene alguna duda sobre el estudio o siente que sus derechos fueron vulnerados, puede contactar al presidente del Comité de Ética en Investigación de la Universidad Peruana de Ciencias Aplicadas, Dr. Rodrigo Rondón al teléfono 313-3333, anexo: 2678 o al correo electrónico rodrigo.rondon@upc.pe. 
El comité de ética está formado por personas externas al proyecto de investigación, cuya función es velar que se respete la dignidad y derecho de los participantes, según el diseño y desarrollo de la investigación.

\section{Derecho a retirarse}

Usted podrá retirarse en cualquier momento del estudio sin ninguna explicación al respecto.

Nombre del participante:

Firma:

Fecha:

Nombre del investigador que administra el consentimiento:

Firma

Fecha:

En el caso de menores de 18 años o participantes que tengan alguna limitación mental que los incapacite a firmar el consentimiento informado, se reconocerá como su representante al padre, la madre o algún otro familiar o apoderado. Los analfabetos podrán utilizar su huella digital (dedo índice) en lugar de la firma. Una copia del documento de consentimiento informado siempre debe ser entregado al firmante.

Los menores de edad (de 10 a 18 años) además deberán dar su asentimiento de participación en la investigación. Sí se niegan no podrá realizarse la investigación en ellos, así su representante legal esté de acuerdo con firmar el documento de consentimiento informado. 